\title{
Use of an oestrogen, androgen or gestagen as a potential chemosterilant for control of rat and mouse populations
}

\author{
Y. Gao and R. V. Short \\ Department of Physiology, Monash University, Melboume, Victoria, Australia 3168
}

\begin{abstract}
Three synthetic steroids were evaluated as potential chemosterilants for rodent control. Ethinyl oestradiol, methyl testosterone or Org 5933, a synthetic gestagen, were incorporated into paraffin blocks containing cereal grains and offered to laboratory rats and mice in addition to their standard laboratory diet. Ethinyl oestradiol (50 $\mathrm{mg} \mathrm{kg}^{-1}$ paraffin block) was highly unpalatable to female rats, and the amount of steroid ingested was not sufficient to interfere with their oestrous cycles or inhibit ovulation. Methyl testosterone $\left(5000 \mathrm{mg} \mathrm{kg}^{-1}\right.$ paraffin block), although not as palatable as untreated blocks, was effective in inducing almost immediate infertility in female rats and mice at an ingested dose of about $35 \mu \mathrm{g} \mathrm{g}^{-1}$ body weight day ${ }^{-1}$. This infertility persisted throughout the duration of treatment, and lasted for several weeks after the cessation of treatment. Male rats became infertile after 3 months of treatment owing to suppression of spermatogenesis. Female rats developed a specific aversion to methyl testosterone when they were pregnant or lactating; it was therefore not possible to masculinize the brains of their female offspring. In mice, the androgen treatment induced high levels of aggression in the females so that they fought with males and with one another. One female died of her wounds. Org 5933 (4 $\mathrm{mg} \mathrm{kg}^{-1}$ paraffin block) was highly palatable to female rats and mice, and at doses of about $420 \mathrm{ng} \mathrm{g}^{-1}$ body weight day ${ }^{-1}$ was effective in inhibiting ovulation in rats within 3 to 4 days after the start of treatment. This infertility persisted throughout the duration of treatment, and the animals conceived within 5 days of cessation of treatment. A dose of about $930 \mathrm{ng} \mathrm{g}^{-1}$ body weight day ${ }^{-1}$ was not completely effective in inhibiting ovulation in mice, but females that became pregnant during treatment gave birth to dead young. When the gestagen was given to female rats and mice in the last few days of pregnancy, the duration of gestation was significantly prolonged, and most young were born dead; some of the females also died in labour. The gestagen did not appear to inhibit lactogenesis, since the few animals that gave birth to live young reared them normally for the first 5 days of life. These results show that either methyl testosterone or Org 5933 in paraffin blocks could perhaps be used as a chemosterilant for the control of rat and mouse populations. The optimal strategy would be to use the chemosterilant when the population density of rodents was lowest, for example at the end of the winter, or following a poisoning campaign with conventional rodenticides, thereby preventing the survivors from reproducing and spreading genetic resistance to the poison.
\end{abstract}

\section{Introduction}

Rodents have become major parasites of all human civilizations. Not only are they vectors of many human diseases, such as plague, leptospirosis, typhus and salmonellosis, but they also destroy an estimated $20 \%$ of the harvested crops of the world during storage, and can do major damage to buildings and equipment (Meehan, 1984). Globally, they do billions of dollars of damage a year. New approaches to rodent control are therefore required.

The conventional way of controlling populations of rats or mice has been to use one of a number of commercially available poisons (Meehan, 1984). Under optimal conditions such poison-

Received 6 December 1991. ing campaigns can be extremely effective. However, there are usually a few individuals that survive the poisoning. These may be individuals that have failed to ingest sufficient poisoned bait because of bait shyness, and there may be individuals in the population that are genetically resistant to the poison in question. Whatever the reason, these survivors can reproduce rapidly to produce a new plague, and there will be a strong selection pressure to favour the spread of genetic resistance to the poison. This has certainly occurred in the case of resistance to warfarin, one of the most widely used anticoagulant poisons, and resistance is now developing to difenacoum, one of the second generation anticoagulants (Greaves, 1985).

An alternative to poisoning would be the use of a chemosterilant that prevented the target species from reproducing. Knipling and McGuire (1972) have shown by computer modell- 
ing that administration of a poison with a $70 \%$ kill rate in both sexes to rats over three successive generations would produce only a transitory decline in the population, whereas administration of an irreversible chemosterilant that was $70 \%$ effective in both sexes over three successive generations would result in extinction of the species within 12 generations. In spite of this theoretical advantage of chemosterilants over conventional poisons, little research has been done on chemosterilants in the past two decades (Bomford, 1990).

Knipling (1959) was the first to suggest using sterile males for rodent control, and was followed by Davis (1961) who suggested use of chemosterilants. Many potential chemosterilants were screened in the late 1960s and early 1970s (Marsh and Howard, 1973; Meehan, 1984; Marsh, 1988). But up to now, only one substance, $\alpha$-chlorohydrin, has been found to be effective, and then only for rats. It was shown to be highly toxic to male and female rats, killing $85 \%$ and leaving the mature male survivors sterile (Andrews and Belknap, 1983). $\alpha$-Chlorohydrin is not palatable to rats, but microencapsulation can increase its acceptability, although the consumption of a diet containing microencapsulated $\alpha$-chlorohydrin was only half that of the basal diet (Ericsson et al., 1971). a-Chlorohydrin has no antifertility effect in juvenile male rats, female rats, or in mice of either sex.

The optimal strategy for using a chemosterilant for rodent control would be to use it in combination with a conventional poisoning campaign (Howard, 1967; Marsh and Howard, 1973). The target population would first be poisoned to reduce the numbers as rapidly and effectively as possible. The survivors could then be chronically exposed to the chemosterilant in a different bait, thereby not only preventing a population rebound, but also inhibiting the development of strains resistant to the initial poison. Another way of using a chemosterilant would be to use it when the population was at a nadir, for example, at the end of winter, thereby preventing numbers from increasing in the spring. If the effect of the chemosterilant was rapidly reversible, this would overcome the potential problem of secondary poisoning of nontarget predators which might feed on the target species.

One of the problems with maintaining continuous chronic exposure to a chemosterilant at a baiting station is to ensure that the bait is highly palatable to the target species, especially when there may be an abundance of alternative foods. It is also essential for the chemosterilant to achieve a high degree of species specificity. One way of targeting rats and mice very effectively is to incorporate the chemosterilant into paraffin wax blocks which also contain some cereal grains (Bajomi et al., 1976). Rats and mice have a particular predilection for chewing cereal grains in paraffin wax, preferring this to the standard laboratory diet. Paraffin blocks are ideally suited to chronic administration since the chemosterilant is not leached out by rain, or decomposed by exposure to sunlight, moisture, oxidation or bacterial contamination, and the block is unlikely to be consumed by humans, carnivores, or birds.

The object of the present experiments was to determine whether any of the three classes of reproductive steroids, oestrogens, androgens or gestagens, could be successfully administered in paraffin blocks chronically to rats or mice in a free-choice feeding situation to inhibit their reproduction.

\section{Materials and Methods}

\section{Animals}

Sexually mature male and female Long Evans rats and BALB/c mice were used; the animals were kept in a cycle of $12 \mathrm{~h}$ light: $12 \mathrm{~h}$ dark and given water ad libitum and a standard laboratory $\operatorname{diet}$ (G2 +; King and Co., North Melbourne). This balanced diet consisted of wheat meal, soybean meal, linseed meal, rice pollard, meat meal, molasses, vitamins, minerals, salts, calcium and phosphorus.

\section{Steroids}

Ethinyl oestradiol and methyl testosterone were purchased from Sigma Chemical Company (St Louis, MO). A potent new orally active gestagen, Org 5933 (16a-ethyl-21-hydroxy-D4,919-norpregnadiene-3,20-dione), was supplied by the Pharma Division of Organon International (Oss, The Netherlands).

\section{Baits and diets}

Paraffin wax (Paraplast, melting point $56^{\circ} \mathrm{C}$, Monoject Scientific, St Louis, MO) was first melted in an oven at $65^{\circ} \mathrm{C}$. The required amount of steroid was added to the melted paraffin which was stirred on a hot plate for $20 \mathrm{~min}$. A mixture of blended cereals was then added to give a ratio of $26 \%$ paraffin: $74 \%$ mixed cereals (wheatmeal $29 \%$, cornmeal $28 \%$, oatmeal $28 \%$, canary seed $7 \%$, sugar $7 \%$ and defatted milk powder $1 \%$ ). After mixing well, blue dye (Queen Fine Foods Pty Ltd, Queensland) was added for the purpose of identification $(3 \mu \mathrm{l}$ dye: $\mathrm{g}$ cerealparaffin mixture). The paraffin mixture was then poured into plastic dishes, $7 \mathrm{~cm}$ square and $1 \mathrm{~cm}$ deep, and allowed to set, to give individual paraffin blocks weighing approximately $35 \mathrm{~g}$ when containing ethinyl oestradiol or methyl testosterone, or $25 \mathrm{~g}$ when containing Org 5933. Untreated control paraffin blocks were prepared in the same way but without the addition of any steroid.

\section{Treatment groups}

Ethinyl oestradiol. Eighteen female rats were weighed and assigned at random to six groups of three animals per cage. In addition to the standard laboratory diet, they were given untreated paraffin blocks, or paraffin blocks containing either 50 , $100,200,500$ or $1000 \mathrm{mg}$ ethinyl oestradiol $\mathrm{kg}^{-1}$ block for three periods of 6 days, separated by periods of 2 days with no treatment. This 2 day discontinuation was to assess reacceptability of a bait. The block was suspended inside the cage by a wire, and sawdust bedding was excluded from the area beneath the block by a wooden partition so that any chewed but non-ingested block could be weighed. Food intake of the laboratory diet and paraffin blocks was recorded every other day throughout the treatment period by weighing the food remaining in the hoppers and weighing the paraffin blocks. Vaginal smears were taken daily to see if ingestion of ethinyl oestradiol could inhibit ovulation. On day 23 after the start of treatment, untreated male rats were caged with the females for 
19 days. The females were then separated and caged singly, and observed daily for signs of preganncy or birth. Dates of birth and number of offspring were recorded as the index of female fertility.

Methyl testosterone. In an experiment to determine dose of methyl testosterone, 18 female rats were weighed and assigned at random to six groups of three animals per cage. In addition to the standard laboratory diet, they were given untreated paraffin blocks or paraffin blocks containing either 200,500, 1250, 2500 or $5000 \mathrm{mg}$ methyl testosterone $\mathrm{kg}^{-1}$ block for three periods of 6 days, separated by periods of 2 days with no treatment. Food intake and female fertility were monitored as in the ethinyl oestradiol experiment. In addition, fertile males were caged with any females that had not produced young in the first 40 days after cessation of treatment, to determine when their fertility eventually returned.

In a long-term study of contraceptive efficacy, 18 female rats were weighed and randomly assigned to one control or two treatment groups of six animals which were given untreated paraffin blocks or paraffin blocks containing 500 or $5000 \mathrm{mg}$ methyl testosterone $\mathrm{kg}^{-1}$ block in addition to the standard laboratory diet for 98 days. For the first 8 days of the treatment they were caged individually. On day 9, females were housed two to a cage and a fertile male was put into each cage for 90 days. The males also had access to the blocks throughout this period.

During the treatment period, any females that had become pregnant at lower doses of methyl testosterone and were close to parturition were caged individually, and the dates of birth and number of young were recorded. For the first 20 days of lactation, daily intake of the paraffin blocks was recorded. If any of the treated females produced young, on day 21 of lactation one female from each litter was randomly selected and kept for fertility tests in adulthood, and the remaining young were killed. At about 90 days of age, vaginal smears from the surviving young were examined daily for 6 days to determine whether oestrous cycles were occurring. The females were then paired with fertile males to test their fertility.

After the end of the methyl testosterone treatment period, all the adult females were killed. Their ovaries, uteri and pituitary glands were weighed and fixed in Bouin's solution for histological study. Six nonpregnant rats of about the same age were used to provide additional histological controls.

The males that had been caged with the experimental females were caged with untreated females to check male fertility after exposure to the androgen for 90 days. The males were then killed. Their testes, epididymides, seminal vesicles, ventral prostates and pituitary glands were weighed and fixed in Bouin's solution for histological study; the left testis and epididymis were not fixed, but were used for assessment of spermatozoon content and motility.

The left testis was decapsulated and homogenized in Triton buffer $\quad 0.9 \%$ sodium chloride, $0.05 \%$ Triton-X-100, $0.01 \%$ sodium azide) for $20 \mathrm{~s}$ using a tissue homogenizer (UltraTurrex: Janke and Kunkel GmbH \& Co., KG, Ika-Werk Staufen). Nuclei of elongated spermatids and spermatozoa in an aliquot of the suspension were counted using a haemocytometer under a microscope. Spermatozoa from the caput, corpus and cauda of the left epididymis were also counted. The individual tissue was very finely diced on a wax-plastic sheet and then squeezed by using forceps and washed by using a known volume of Tyrode's solution $(0.05 \mathrm{~g}$ sodium diphosphate, $1 \mathrm{~g}$ glucose, $0.2 \mathrm{~g} \mathrm{KCl}, 8 \mathrm{~g} \mathrm{NaCl}, 0.1 \mathrm{~g} \mathrm{MgCl}$, $1 \mathrm{~g} \mathrm{NaHCO}_{3}$, and $0.2 \mathrm{~g} \mathrm{CaCl}_{2}$ in $1 \mathrm{l}$ distilled water, $\mathrm{pH} 7.5$ ) until none or very few spermatozoa were seen in the solution under a microscope. Then spermatozoa in an aliquot of the pooled washings were counted as for the testicular spermatozoa.

Spermatozoan motility was assessed by mixing a very small volume of the contents of the cauda epididymis with Tyrode's solution in a test tube previously warmed to $37^{\circ} \mathrm{C}$ in a water bath. Motile and immotile spermatozoa in a small aliquot of the suspension were counted on a glass slide under a microscope that had previously been warmed to $37^{\circ} \mathrm{C}$, and the grade of motility was assessed according to the World Health Organization Laboratory Manual (1987).

The diameter of the seminiferous tubules in histological sections of the testis were measured by measuring ten of the roundest tubules in cross-section (mean of the greatest and least diameters of each tubule) using a projection microscope together with a micrometer. The measurements were then averaged to give the mean seminiferous tubule diameter for this particular animal.

In a long-term study of female mice, 12 females were weighed and assigned at random to control or treatment groups of six animals. In addition to the standard laboratory diet, the animals were given untreated paraffin blocks or paraffin blocks containing $5000 \mathrm{mg}$ methyl testosterone $\mathrm{kg}^{-1}$ block for 98 days. For the first 8 days the animals in each group were caged together, and from day 9 , they were housed two to a cage and an untreated, fertile male was introduced into each cage and any young subsequently produced were recorded. The males were replaced monthly by fresh, fertile males. The animals were weighed on days 39,69 and 99 of treatment. At the end of the treatment period, the females were killed and their ovaries and uteri weighed and fixed in Bouin's solution for histological study. Six nonpregnant female mice of about the same age were used to provide additional body weight and histological controls.

The gestagen Org 5933. In a study of nonpregnant rats, 12 females were caged singly and vaginal smears were examined daily for 5 days to assess the normality of their oestrous cycles. They were then weighed and assigned at random to control or treatment groups of six animals that were given untreated paraffin blocks or paraffin blocks containing $4 \mathrm{mg}$ Org 5933 $\mathrm{kg}^{-1}$ block for 38 days, in addition to the standard laboratory diet. Food intake was recorded daily for the first 8 days of treatment, and during this period vaginal smears were also examined daily to see if ovulation had been inhibited. From day 9 of treatment, an untreated male was introduced into each cage overnight without being offered the paraffin blocks. Dates of birth and number of live young were recorded. On day 39, the treatment was stopped and any young that had been born were 
killed. The adult females were then housed continuously with the same males until they gave birth; dates of birth and number of young were recorded to determine the time for return of fertility following cessation of treatment.

In a study of pregnant rats, 14 nonpregnant females were weighed and assigned at random to control $(n=6)$ or treatment ( $n=8$ ) groups, and caged singly. A male was then put into each cage and the animals were checked daily for vaginal plugs as evidence of mating. The day of mating was defined as day 0 of pregnancy. From day 18 of pregnancy, the females were offered untreated paraffin blocks or paraffin blocks containing $4 \mathrm{mg}$ Org $5933 \mathrm{~kg}^{-1}$ block, in addition to the standard laboratory diet, until day 5 of lactation (the day of birth was defined as day 0 of lactation). Consumption of the paraffin blocks was recorded daily between day 18 and day 21 of pregnancy. Dates of birth and number of live young were recorded.

In a long-term study of nonpregnant mice, 18 animals were caged singly and vaginal smears were examined daily for 5 days to assess the normality of their oestrous cycles before treatment started. They were then weighed and assigned randomly to three groups of six animals that were given untreated paraffin blocks or paraffin blocks containing 0.4 or $4 \mathrm{mg}$ Org $5933 \mathrm{~kg}^{-1}$ block for 65 days, in addition to the standard laboratory diet. Vaginal smears were examined for a further 5 days to determine whether the treatment had inhibited ovulation, and food intake was recorded daily for 5 days and subsequently at 15 day intervals. From day 6 of treatment, the females were caged with untreated males which also had access to the paraffin blocks. The males were replaced monthly by fresh, untreated males. Dates of birth and number of young were recorded.

In a study of pregnant mice, 12 nonpregnant females were weighed and assigned at random to control or treatment groups of six animals, and caged singly. The experimental design was similar to that for pregnant rats, but treatment started from day 16 instead of day 18 of pregnancy, and consumption of the paraffin blocks was recorded daily between day 16 and day 19 of pregnancy.

\section{Analysis of data}

Results are shown as means \pm SEM throughout. Comparisons between means were made using the unpaired $t$ test, unless otherwise indicated. 'Not significant' implies $P>0.05$.

\section{Results}

\section{Effects of ethinyl oestradiol on rats}

The average intake of treated blocks was very low in all treatment groups during the first two days of treatment, less than $1 \mathrm{~g}$ per rat per day versus $17.4 \mathrm{~g}$ per rat per day of the untreated blocks, giving an average consumption of ethinyl oestradiol of $0.08,0.49,0.92,1.68$ or $3.49 \mu \mathrm{g} \mathrm{g}^{-1}$ body weight day $^{-1}$ respectively for the animals given paraffin blocks containing either $50,100,200,500$ or $1000 \mathrm{mg}$ ethinyl oestradiol $\mathrm{kg}^{-1}$ block. During days 3 and 4 , consumption declined even further in the treatment groups, and after day 4 , none of the treated animals consumed any of the blocks throughout the remainder of the treatment period. The average daily consumption of the blocks for all treatment periods is shown (Fig. 1). Ingestion of ethinyl oestradiol during the first 2 days of treatment did not obviously affect the duration of subsequent oestrous cycles, as judged by vaginal smears.

All treated females gave birth $27.1 \pm 5.5$ days after introduction of untreated males in the post-treatment phase. This did not differ significantly from the timing of birth in the controls $(29.0 \pm 5.6$ days). The average litter size did not differ significantly between the treated $(8.5 \pm 3.2$ young per litter) and control $(9.7 \pm 4.0$ young per litter) animals.

It was concluded that ethinyl oestradiol, even at a concentration as low as $50 \mathrm{mg} \mathrm{kg}^{-1}$ block, immediately rendered the paraffin blocks extremely unpalatable to female rats, so that no animal ingested sufficient oestrogen to interfere with the oestrous cycle or depress fertility. No studies were therefore undertaken in mice.

\section{Methyl testosterone}

Effects on rats. The animals given the higher concentration blocks showed decreased bait consumption. The mean consumption of methyl testosterone was $9.8 \pm 2.1$, $16.6 \pm 2.0$, $17.5 \pm 2.5$ or $15 \pm 2.7 \mu \mathrm{gg}^{-1}$ body weight day ${ }^{-1}$, respectively for the animals given paraffin blocks containing 200,500, 1250 or $2500 \mathrm{mg}$ methyl testosterone $\mathrm{kg}^{-1}$ block (Fig. 1). It was not possible to measure consumption of the paraffin blocks containing $5000 \mathrm{mg}$ methyl testosterone $\mathrm{kg}^{-1}$ block, as after the first 2 days the animals gnawed the whole block into small pieces and scattered them around the cage. This phenomenon was also observed in other methyl testosterone experiments when a high concentration of steroid was used, but it was not observed at the lower methyl testosterone concentrations. The average intake of the $5000 \mathrm{mg} \mathrm{kg}^{-1}$ blocks during the first 2 days of treatment was $1.2 \mathrm{~g}$ per rat per day, giving a consumption of $34.5 \mu \mathrm{g} \mathrm{g}^{-1}$ body weight day ${ }^{-1}$ of methyl testosterone. The mean intake of the standard laboratory diet for the controls or the treated animals given paraffin blocks containing 200,500, 1250,2500 or $5000 \mathrm{mg}$ methyl testosterone $\mathrm{kg}^{-1}$ block was $1.6 \pm 0.3,5.5 \pm 0.9,7.2 \pm 0.5,10.4 \pm 0.6,10.8 \pm 0.7$ or $12.7 \pm 1.1 \mathrm{~g}$ per rat per day, respectively, indicating a high palatability of the untreated bait and showing that as the concentration of methyl testosterone in the blocks was increased, the animals increasingly preferred the standard laboratory diet to the blocks.

When daily consumption of the blocks was analysed within a group between the first and the other two treatment periods (the paired $t$ test), there was no significant difference in the control and the first three treatment groups given the 200,500 or $1250 \mathrm{mg}$ methyl testosterone $\mathrm{kg}^{-1}$ blocks, but the intake in the third treatment period was significantly depressed in animals given paraffin blocks containing $2500 \mathrm{mg}$ methyl testosterone $\mathrm{kg}^{-1}$ block $(P<0.05)$, indicating that the methyl testosterone block had a poor re-acceptability at high methyl testosterone concentrations.

On the basis of the vaginal smears, ingestion of paraffin blocks treated with methyl testosterone at all concentrations used inhibited oestrous cycles in female rats after about day 3 of 

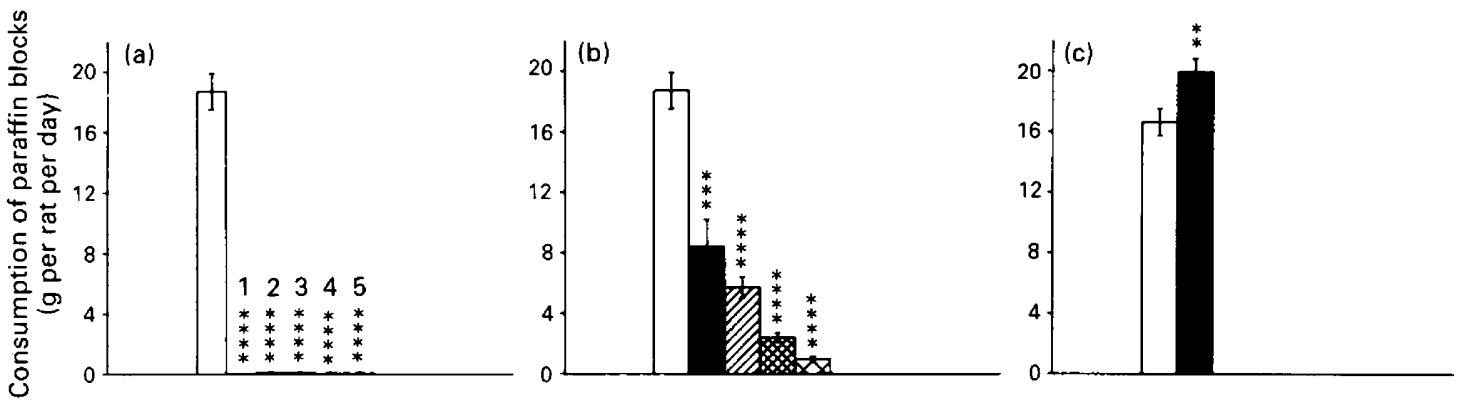

Fig. 1. Mean ( \pm SEM) daily consumption of steroid-treated paraffin blocks versus untreated control paraffin blocks by female rats in free-choice feeding trials in the presence of their standard laboratory diet. (a) The ethinyl oestradiol blocks containing different concentrations of steroid were given to the animals for three periods of 6 days at intervals of 2 days: (口) control; (1) $50 \mathrm{mg}$ steroid kg-1; (2) $100 \mathrm{mg}$ steroid $\mathrm{kg}^{-1}$; (3) $200 \mathrm{mg}$ steroid $\mathrm{kg}^{-1}$; (4) $500 \mathrm{mg}$ steroid kg-1; (5) $1000 \mathrm{mg}$ steroid $\mathrm{kg}^{-1}$. (b) The methyl testosterone blocks containing different concentrations of steroid were given to the

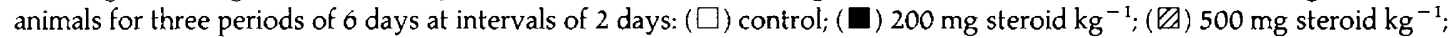
( $1250 \mathrm{mg}$ steroid kg-1; (囚) $2500 \mathrm{mg}^{-1}$ steroid kg-1. (c) The Org 5933 blocks were given to the animals for 8 successive days: $(\square)$ control; ( $\square$ ) $4 \mathrm{mg}$ steroid $\mathrm{kg}^{-1}$. ${ }^{* *}: P<0.01 ;{ }^{* * *}: P<0.001 ;{ }^{* * * *}: P<0.0001$ compared with control values.

treatment. The smears were characterized by strings of mucus containing large numbers of small, round, nucleated epithelial cells, cornified cells and leucocytes. In contrast, the smears from control animals did not contain mucus.

On introduction of male rats to the untreated females, the males very soon started to investigate the genitalia of the females and then tried to mount them by force. In contrast, the males that were introduced to methyl testosterone treated females were almost immediately approached and sniffed by the females, especially in the area under the tail. Forced mounting of treated females was never observed in the hours immediately after the introduction of the males, and there was no fighting.

After the cessation of treatment with the $5000 \mathrm{mg}$ methyl testosterone $\mathrm{kg}^{-1}$ paraffin blocks, conception was prevented for at least 19 days, but the fertility of the females returned within the following 3 weeks. The controls and almost all the females in the lower dose treatment groups conceived within one to two weeks of being caged with the males following cessation of treatment. There was no statistically significant difference in litter size between the groups.

In a long-term study of female rats, all the females given paraffin blocks containing $500 \mathrm{mg}$ methyl testosterone $\mathrm{kg}^{-1}$ block gave birth $31.2 \pm 2.9$ days after introduction of males; this was significantly later than $24.5 \pm 1.0$ days in the untreated controls $(P<0.05)$. There was no significant difference in litter size between the two groups. Fertility of all six females given the $5000 \mathrm{mg}$ methyl testosterone $\mathrm{kg}^{-1}$ blocks was totally suppressed throughout the three months that they were caged with males.

The ovaries and pituitary glands of the rats treated with $5000 \mathrm{mg}$ methyl testosterone $\mathrm{kg}^{-1}$ blocks were half the weight of those of the control females, but there was no significant difference in uterine weight between the two groups (Table 1).

Histological examination showed that the ovaries of the animals treated with $5000 \mathrm{mg} \mathrm{kg}^{-1}$ blocks were quiescent, with no large Graafian follicles or corpora lutea (Fig. 2). Only one of six treated animals had ovaries with corpora albicantia. There were no new corpora lutea in any of the ovaries of the treated animals, indicating that the treated females probably had not ovulated since the treatment started.
Table 1. Organ weights of female rats fed paraffin blocks with or without $5000 \mathrm{mg}$ methyl testosterone $\mathrm{kg}^{-1}$ block in the presence of the standard laboratory diet for 98 days

\begin{tabular}{lccc}
\hline Groups & $\begin{array}{c}\text { Weight of } \\
\text { each ovary } \\
(\mathrm{mg})\end{array}$ & $\begin{array}{c}\text { Weight of } \\
\text { uterus } \\
(\mathrm{mg})\end{array}$ & $\begin{array}{c}\text { Weight of } \\
\text { pituitary gland } \\
(\mathrm{mg})\end{array}$ \\
\hline $\begin{array}{l}\text { Control rats } \\
(n=6)\end{array}$ & $23.2 \pm 1.2$ & $373.0 \pm 31.3$ & $14.0 \pm 1.0$ \\
$\begin{array}{l}\text { Treated rats } \\
(n=6)\end{array}$ & $11.1 \pm 2.9$ & $309.0 \pm 42.4$ & $7.9 \pm 0.6$ \\
\begin{tabular}{l}
$P$ value \\
\hline
\end{tabular} & $<0.01$ & $>0.05$ & $<0.001$ \\
\hline
\end{tabular}

Values given are means \pm SEM.

The males that had been exposed to the $5000 \mathrm{mg} \mathrm{kg}^{-1}$ treated blocks were caged with untreated females after the end of the 3 months of treatment. However, they failed to sire any young as a result of matings in the first 5 days after treatment ceased. Spermatogenesis was severely depressed, as assessed by testicular weight (Table 2), histological appearance (Fig. 2) and testicular content of spermatozoa (Fig. 3). In contrast, all the males that had been caged with the control females successfully sired young and their spermatogenesis appeared normal. Mean diameter of the ten roundest seminiferous tubules from each testicular section of the treated males was significantly smaller than that of the control males $(0.18 \pm 0.02 \mathrm{~mm}$ versus $0.27 \pm 0.01 \mathrm{~mm}, P<0.05, n=3$ ). Percentage of motile spermatozoa in the cauda epididymis of the treated males was significantly lower and the percentage of immotile spermatozoa in the same tissue was significantly higher than that in the cauda epididymis of the controls (Fig. 4).

An aversion of female rats to paraffin blocks containing $500 \mathrm{mg}$ methyl testosterone $\mathrm{kg}^{-1}$ block was noted during lactation. The females in the control group consumed untreated blocks at about the same rate as nonpregnant animals. However, the treated rats consumed only $0.34 \mathrm{~g}$ per rat per day of the treated blocks during the first 16 days of lactation, followed 

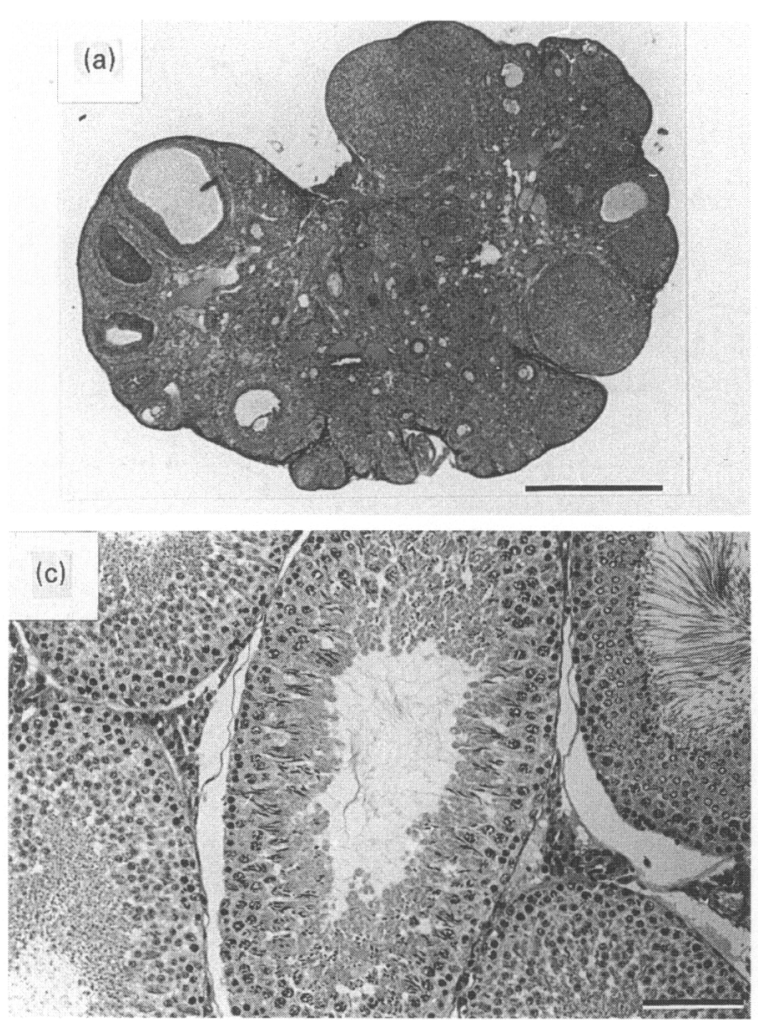

(b)
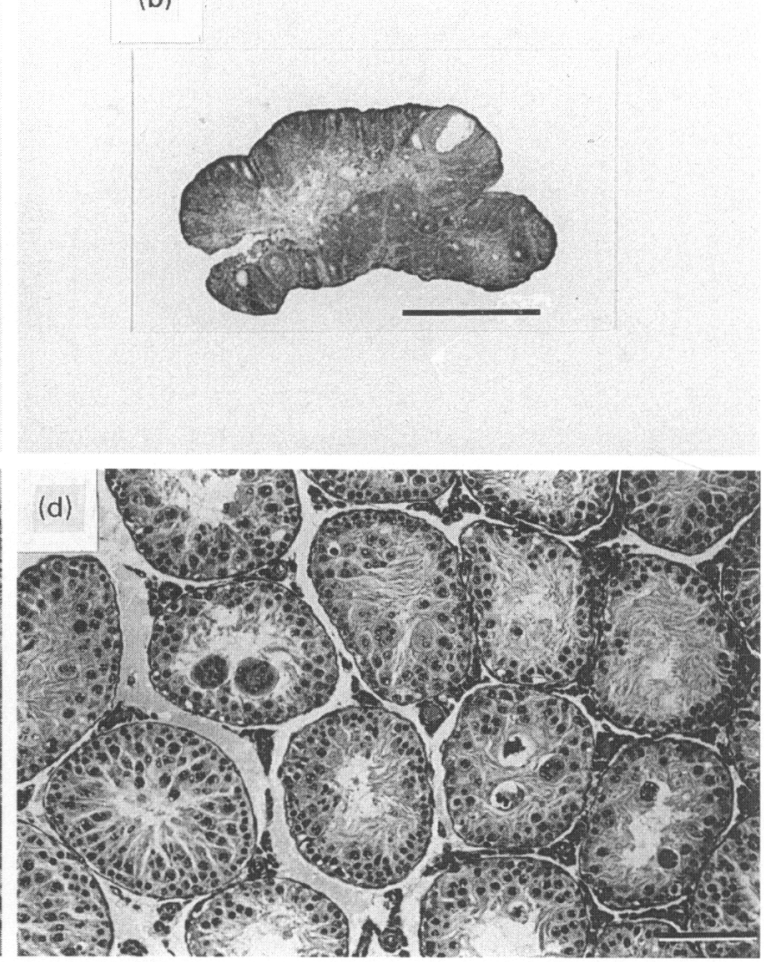

Fig. 2. (a) Cross-section of the ovary of an untreated control rat (the bar is equivalent to $1 \mathrm{~mm}$ ). (b) Cross-section of the ovary of a rat fed paraffin blocks containing $5000 \mathrm{mg}$ methyl testosterone $\mathrm{kg}^{-1}$ block in the presence of the standard laboratory diet for 98 days (the bar is equivalent to $1 \mathrm{~mm}$ ). (c) Cross-section of the testis of an untreated control rat (the bar is equivalent to $0.5 \mathrm{~mm}$ ). (d) Cross-section of the testis of a rat fed paraffin blocks containing $5000 \mathrm{mg}$ methyl testosterone $\mathrm{kg}^{-1}$ block in the presence of the standard laboratory diet for 98 days (the bar is equivalent to $0.5 \mathrm{~mm}$ ).

Table 2. Organ weights of male rats fed paraffin blocks with or without $5000 \mathrm{mg}$ methyl testosterone $\mathrm{kg}^{-1}$ block in the presence of the standard laboratory diet for 90 days

\begin{tabular}{lccccc}
\hline & $\begin{array}{c}\text { Weight of } \\
\text { testis } \\
(\mathrm{mg})\end{array}$ & $\begin{array}{c}\text { Weight of } \\
\text { epididymis } \\
(\mathrm{mg})\end{array}$ & $\begin{array}{c}\text { Weight of } \\
\text { seminal vesicle } \\
(\mathrm{mg})\end{array}$ & $\begin{array}{c}\text { Weight of } \\
\text { ventral prostate } \\
(\mathrm{mg})\end{array}$ & $\begin{array}{c}\text { Weight of } \\
\text { pituitary gland } \\
(\mathrm{mg})\end{array}$ \\
\hline $\begin{array}{l}\text { Control rats } \\
(n=3)\end{array}$ & $1727.3 \pm 60.0$ & $647.5 \pm 10.0$ & $555.0 \pm 20.0$ & $636.0 \pm 32.0$ & $12.6 \pm 0.4$ \\
$\begin{array}{l}\text { Treated rats } \\
(n=3)\end{array}$ & $663.0 \pm 220.0$ & $395.2 \pm 30.0$ & $531.0 \pm 20.0$ & $653.0 \pm 47.0$ & $10.9 \pm 0.4$ \\
\begin{tabular}{l}
$P$ value \\
\hline
\end{tabular} & $<0.01$ & $<0.01$ & $>0.05$ & $>0.05$ & $>0.05$ \\
\hline
\end{tabular}

Values given are means \pm SEM.

by a sharp increase in consumption of the blocks, which might have been due to the young starting to eat the blocks. In comparison, nonpregnant females consumed about $5 \mathrm{~g}$ of the treated blocks per rat per day. This aversion had probably started during pregnancy, but since the female was caged with the male until late pregnancy it was not possible to monitor the food intake of the females. This aversion of female rats to treated blocks during pregnancy and lactation was confirmed in other experiments (Gao, 1990a).

There was no evidence to suggest that the fertility of the female offspring of rats treated during pregnancy and lactation was inhibited, as they all had normal oestrous cycles as judged by their vaginal smears at about 90 days of age, and they all subsequently gave birth to young after being caged with males.

In summary, although paraffin blocks containing $5000 \mathrm{mg}$ methyl testosterone $\mathrm{kg}^{-1}$ block were not as palatable as the untreated blocks to female rats in a free-choice feeding trial, this concentration was effective in producing almost immediate infertility in the females, and this persisted throughout the course of treatment and for several weeks thereafter. Methyl testosterone at this dose also induced male sterility. The $500 \mathrm{mg}$ methyl testosterone $\mathrm{kg}^{-1}$ blocks could not prevent 


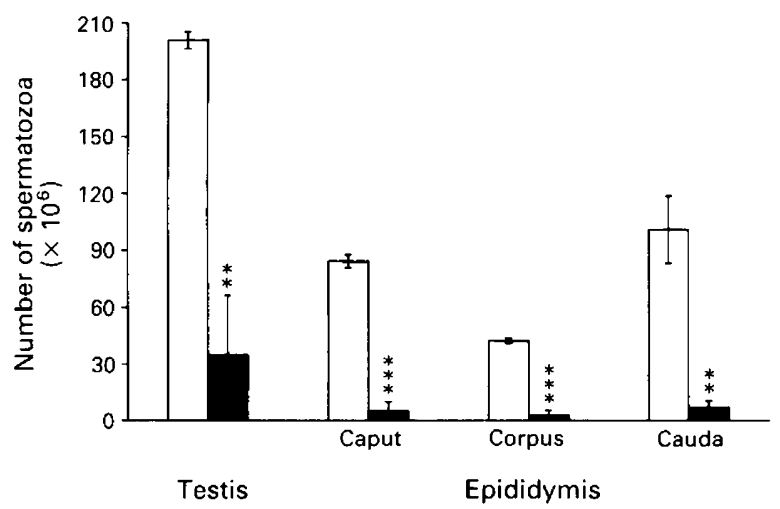

Fig. 3. Number of spermatozoa in the testis and epididymis of rats fed untreated paraffin blocks $(\square)$ or paraffin blocks containing $5000 \mathrm{mg}$ methyl testosterone $\mathrm{kg}^{-1}$ block ( $\mathbf{G}$ ) in the presence of the standard laboratory diet for 90 days. Vertical bars represent SEM. ${ }^{* *}: P<0.01$; ${ }^{* * *}: P<0.001$ compared with control values.

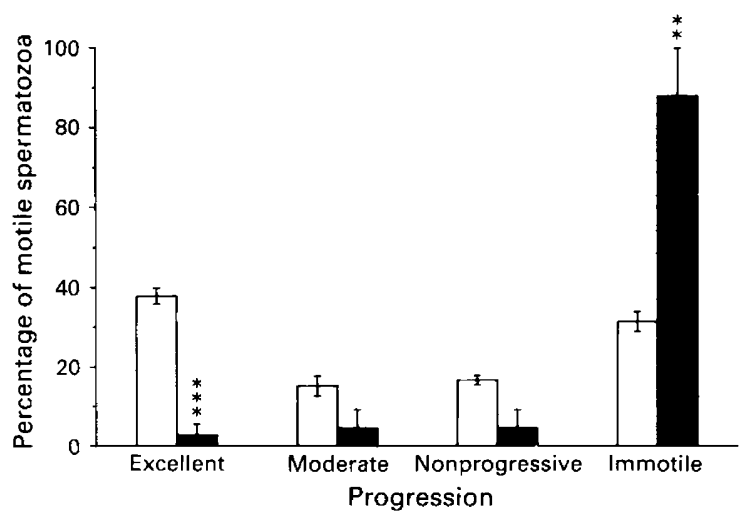

Fig. 4. The motility of spermatozoa from the cauda epididymis of rats fed $(\square)$ untreated paraffin blocks or ( $\square$ ) paraffin blocks containing $5000 \mathrm{mg}$ methyl testosterone $\mathrm{kg}^{-1}$ block in the presence of the standard laboratory diet for 90 days. Excellent: the spermatozoon had a rapid linear movement. Moderate: the spermatozoon had a sluggish linear or non-linear movement. Nonprogressive: the spermatozoon had a nonprogressive movement. Immotile: the spermatozoon was immotile. Values given are means \pm SEM. ${ }^{* *}: P<0.01 ;{ }^{* * *}: P<0.001$ compared with control values.

female rats from conceiving. Female rats developed an aversion to paraffin blocks containing methyl testosterone during pregnancy and lactation. Thus it was not possible to deliver sufficient androgen to the fetuses and neonates to masculinize their brains and hence induce permanent sterility in the female offspring.

Effects on mice. In a long-term study of the $5000 \mathrm{mg}$ methyl testosterone $\mathrm{kg}^{-1}$ paraffin blocks in female mice, all the treated animals failed to produce any young throughout a treatment period of 3 months when caged with males after 8 days of treatment, whereas all the controls gave birth to three litters of young during the same period.
Although the treated females were infertile, the mean ovarian weights were not significantly different from those of the control females $(8.6 \pm 1.1$ versus $10.6 \pm 1.3 \mathrm{mg}$ for each ovary, $P>0.05$ ), and there was no significant difference in uterine weights ( $188.8 \pm 7.5$ versus $155.7 \pm 33.7 \mathrm{mg})$.

Histological examination showed that, although the ovaries of treated animals contained some large follicles, they were becoming atretic; there were no new corpora lutea, indicating that the treated females probably had not ovulated since the treatment started.

As a result of ingestion of the androgen, the body weight of the treated female mice increased significantly. Before the start of treatment the animals in the histological control and treatment groups had identical mean body weights of $21.3 \mathrm{~g}$. However, after 39 days of androgen treatment, the animals in the control group weighed $23.3 \pm 0.5 \mathrm{~g}$, whereas the treatment group weighed $26.1 \pm 0.8 \mathrm{~g}(P<0.05)$; this difference persisted: by day $69,23.8 \pm 0.8$ versus $28.7 \pm 0.6 \mathrm{~g}(P<0.001)$; by day $99,25.1 \pm 0.4$ versus $29.4 \pm 0.8 \mathrm{~g}(P<0.001)$.

On introduction of male mice to the untreated females on day 9 of the experiment, the males very soon started to investigate the genitalia of the females and then tried to mount them by force. No aggression was observed in the control female mice when males were introduced to them. In contrast, the treated females showed aggression to the introduced males. The males were almost immediately approached and sniffed by the females, especially in the area under the tail. After a few minutes the males started to attack the females. The females occasionally fought back, which might induce the males to attack them more frequently. The females generally ran away, although they often showed male-type tail rattling in these interactions. By the following day, all the treated females showed signs of having been severely bitten, and their tails were covered with scars. But even so, when the males continued to attack them they still fought back from time to time. Occasionally the females also attacked one another. Within a week, all the treated females had severe wounds. Their tails and genital areas were covered with scars (see Fig. 5). Twenty days later one of the treated females was killed in a fight. Another female in the same cage was so severely wounded that she had to be killed for humane reasons.

Generally, the females stayed in a corner of the cage, while the male occupied the central area and came to attack the females from time to time. On day 39 of treatment, the male mice were replaced by new males, which were immediately attacked by the treated females as soon as they were put into the cages. The fights were vigorous, with the male and females biting one another; the females also fought among themselves. When the male and female separated, they started rattling their tails before attacking each other again. After a few minutes, the females were invariably defeated. Sporadic fights occurred for the rest of the month. On day 69 of treatment, the males were replaced once more, and there were severe outbreaks of aggression against the introduced male. One new male was driven into a corner of the cage and was defeated by one of the treated females. When this female subsequently approached him he showed a characteristic defensive posture. The females would from time to time sniff the genital area of this male and occasionally bite him. The females occupied the central area of the cage. This situation lasted for a few days, until the females 


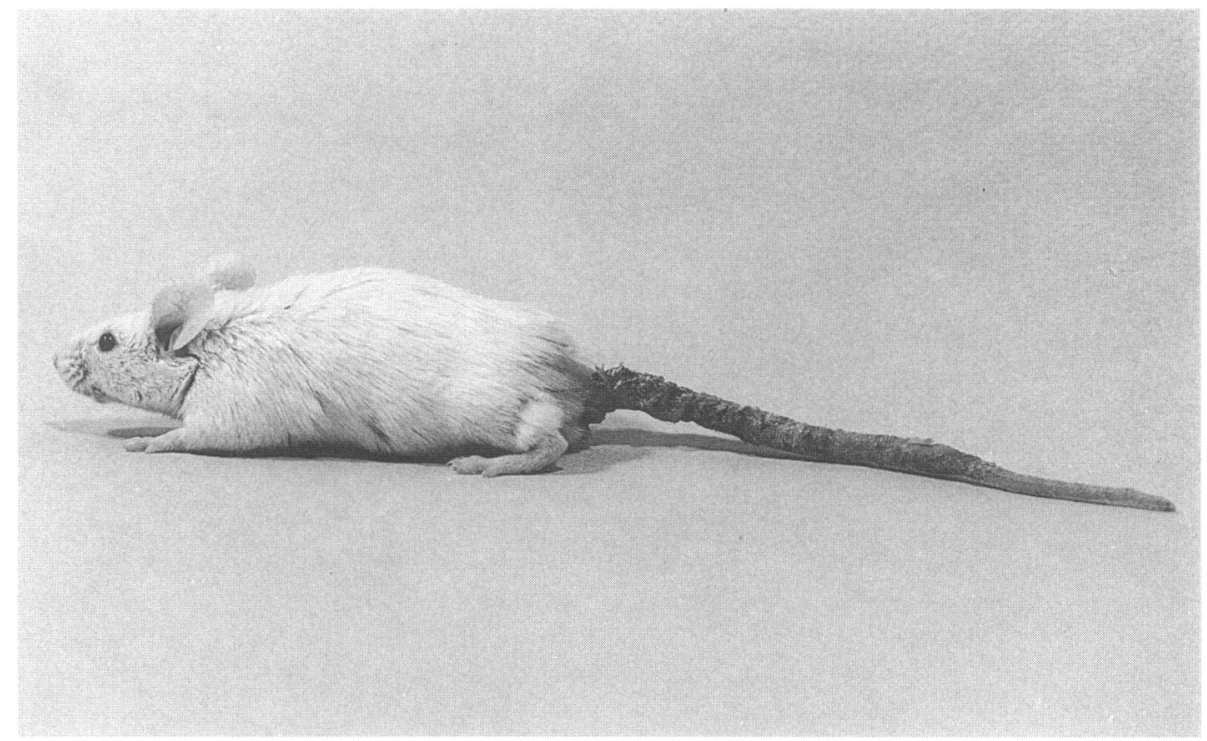

Fig. 5. A female mouse after 30 days of exposure to $5000 \mathrm{mg}$ methyl testosterone $\mathrm{kg}^{-1}$ paraffin block in the presence of the standard laboratory diet, 22 days after introduction of an untreated male. Note extensive scarring of the tail and rump as a result of frequent bites from the male.

gradually allowed the male to mix with them. Towards the end of the month, the male began to attack the females occasionally, indicating that he was reasserting his dominance.

In summary, ingestion of paraffin blocks containing $5000 \mathrm{mg}$ methyl testosterone $\mathrm{kg}^{-1}$ block prevented all the female mice from conceiving throughout the treatment period of 3 months. The androgenized females gained in weight and became increasingly aggressive, fighting with the male and among themselves. These fights resulted in severe wounding and even death.

\section{The gestagen Org 5933}

Effects on rats. In a study of nonpregnant rats, the mean daily consumption of paraffin blocks containing $4 \mathrm{mg}$ Org 5933 $\mathrm{kg}^{-1}$ block by females during the first 8 days of treatment was significantly higher $(P<0.01)$ than that of untreated blocks (Fig. 1), giving an average consumption of $419 \mathrm{ng} \mathrm{g}^{-1}$ body weight day ${ }^{-1}$ of treatment with Org 5933.

All female rats showed normal oestrous cycles, as judged by vaginal smears, during the 5 days before the start of treatment. But 4 days after the start of treatment, the smears of the treated animals contained strings of mucus containing large numbers of metoestrous-type cells. The first 4 days of treatment failed to prevent females progressing from proestrous to oestrous smears.

When caged with males, all the six control females gave birth to litters of live young $24.5 \pm 0.6$ days after the introducton of the males, but none of the six treated females gave birth, and none appeared to be pregnant one month after the introduction of the males.

Treatment was stopped after 38 days and fresh males were introduce the following day. All the controls gave birth to litters of live young $31.2 \pm 0.5$ days later, whereas all the treated animals gave birth to live young $26.6 \pm 1.5$ days later, significantly earlier than the controls $(P<0.05)$.
These results show that paraffin blocks containing $4 \mathrm{mg}$ Org $5933 \mathrm{~kg}^{-1}$ block was highly palatable to female rats, and consumption of the steroid at a dose of about $420 \mathrm{ng} \mathrm{g}^{-1}$ body weight day ${ }^{-1}$ completely inhibited ovulation. But this antifertility effect was rapidly reversible following cessation of treatment.

In a study of pregnant rats, the consumption of both untreated paraffin blocks and paraffin blocks containing $4 \mathrm{mg} \mathrm{Org} 5933 \mathrm{~kg}^{-1}$ block declined in the last few days of pregnancy. The control animals consumed $21.2 \pm 1.6,11.2 \pm 1.9$ and $5.5 \pm 1.6 \mathrm{~g}$ per rat per day on days 19,20 and 21 of pregnancy, while the treated animals consumed $20.9 \pm 1.0,11.3 \pm 0.9$ and $4.4 \pm$ $1.3 \mathrm{~g}$ per rat per day during those 3 days. This difference was not statistically significant between the two groups, indicating that no bait aversion developed. This decline in the block intake probably reflects a decrease in feeding activity of rats in the last stages of pregnancy. The average consumption of Org 5933 was $246 \mathrm{ng} \mathrm{g}^{-1}$ body weight day ${ }^{-1}$ during days 19,20 and 21 of pregnancy.

All the six control females gave birth to litters of live young. In the treatment group, two of the eight animals died in labour on day 25 of pregnancy, three gave birth to litters of dead young between day 24 and day 26 of pregnancy, and the other three gave birth to live litters on day 22 of pregnancy and all the young were still alive on day 5 of lactation, when the experiment was terminated.

The duration of gestation, as judged by the time elapsed from presence of a copulatory plug to the date of birth, was $21.7 \pm 0.2$ days in the control animals versus $23.5 \pm 0.7$ days in the six survivors in the treatment group $(P<0.01)$. This study shows that ingestion of the gestagen during the last few days of pregnancy can postpone parturition, leading to neonatal and even maternal deaths in labour. But, surprisingly, ingestion of the compound did not seem to inhibit lactation, as the young that were born alive survived throughout the first 5 days of lactation. 
Effects on mice. In a long-term study of nonpregnant mice, there was no statistically significant difference in mean daily intake of the control or $0.4 \mathrm{mg} \mathrm{kg}^{-1}$ or $4 \mathrm{mg} \mathrm{kg}^{-1}$ Org 5933 blocks during the first 5 days of treatment $(4.78 \pm 0.2$ versus $4.71 \pm 0.3$ versus $5.06 \pm 0.3 \mathrm{~g}$ per mouse per day), and there was no significant change in consumption of the blocks throughout the remaining treatment period, indicating that the treated blocks were as palatable as untreated blocks. The mean intake of the standard laboratory diet in all the groups was about I g per mouse per day, indicating that the treated paraffin blocks were very palatable to female mice. The average consumption of the steroid in the two treatment groups was $87 \mathrm{ng} \mathrm{g}^{-1}$ body weight day ${ }^{-1}$ or $929 \mathrm{ng} \mathrm{g}^{-1}$ body weight day $^{-1}$.

All the female mice showed normal oestrous cycles, as judged by vaginal smears, before the treatment started, but 3 days after the start of treatment, the smears from the treated females contained strings of mucus containing large numbers of metoestrous-type cells. The first 3 days of treatment failed to prevent females progressing from proestrous to oestrous smears.

When caged with male mice for a month, all the six control females gave birth to litters of live young, whereas in the $0.4 \mathrm{mg} \mathrm{kg}^{-1}$ treatment group only four of the six females gave birth, and half the young were dead. One female died in labour and one animal was not pregnant. In the $4 \mathrm{mg} \mathrm{kg}^{-1}$ treatment group, again only four of the six animals gave birth, but all the young were dead. One female died in labour and one animal was not pregnant. The control females gave birth $26.0 \pm$ 2.7 days after introducton of the males, and the $0.4 \mathrm{mg} \mathrm{kg}^{-1}$ group gave birth after $25.3 \pm 3.3$ days, whereas the $4 \mathrm{mg} \mathrm{kg}^{-1}$ group gave birth after $35.8 \pm 1.5$ days, a significant delay $(P<0.05)$.

After the first births, all the animals remained on treatment. Five of the six control females had second births of live young $23.2 \pm 1.8$ days after the introduction of fresh males; two of the five surviving females from the $0.4 \mathrm{mg} \mathrm{kg}^{-1}$ group gave birth to young 21 or 28 days after the introduction of males, but only $25 \%$ of the young survived. However, in the $4 \mathrm{mg} \mathrm{kg}^{-1}$ group only one of the five surviving females gave birth 28 days after the introduction of a male, and none of the young survived.

Treatment was stopped after 65 days, and the following day fresh males were introduced. The six controls gave birth to live young $29.7 \pm 2.0$ days later; four out of five of the $0.4 \mathrm{mg} \mathrm{kg}^{-1}$ group gave birth to live young $26.5 \pm 1.9$ days later, and all five of the $4 \mathrm{mg} \mathrm{kg}^{-1}$ group gave birth to live young $22.4 \pm 0.7$ days later, a significant difference from the controls $(P<0.05)$.

Thus the gestagen was less effective in mice than in rats for inhibiting ovulation, but there was a pronounced adverse effect on parturition and neonatal survival. As in rats, the effects of the steroid were rapidly reversible following cessation of treatment.

In a study of pregnant mice, the control animals consumed $6.6 \pm 0.7,4.7 \pm 0.5$ and $4.3 \pm 0.9 \mathrm{~g}$ per mouse per day of the untreated blocks on days 17,18 and 19 of pregnancy, whereas the treated animals consumed $4.6 \pm 1.1(P>0.05), 6.6 \pm 0.5$ $(P<0.05)$ and $5.7 \pm 1.0(P>0.05) \mathrm{g}$ per mouse per day of the blocks containing $4 \mathrm{mg}$ Org $5933 \mathrm{~kg}^{-1}$ block on those 3 days, indicating that no bait aversion developed. Unlike rats, there was no decline in the block intake in the last stages of pregnancy. The average intake of the gestagen was $1053 \mathrm{ng} \mathrm{g}^{-1}$ body weight day ${ }^{-1}$

All six control mice gave birth to litters of live young, whereas five of the six treated females gave birth to dead litters. None of the females died in labour. One treated mouse gave birth to live young on day 20 of pregnancy. She then successfully suckled them until day 5 of lactation, when the experiment was terminated.

The six controls gave birth $19.3 \pm 0.2$ days after detection of vaginal plugs, whereas the six treated females gave birth $21.8 \pm 0.4$ days after detection of vaginal plugs, a significant delay $(P<0.01)$.

This clearly shows that ingestion of Org 5933 interfered with parturition, leading to death of neonates. But again, as in rats, it did not seem to inhibit lactation.

\section{Discussion}

The only published reports of the use of steroid hormones as chemosterilants for rodent control are concerned with the use of a range of oestrogens, for example, mestranol, quinoestrol, diethylstilboestrol and BDH 10131. It is claimed that such oestrogens can reduce the fertility of rat or mouse populations. Mestranol coated on dog food was used to control Norway rats at garbage dumps. The bait was applied on three occasions at intervals of about one month. The proportion of young animals captured declined within the first month of treatment, but increased subsequently, indicating a good initial acceptance and a poor re-acceptance of the bait (Marsh and Howard, 1969). Brooks and Bowerman (1971) used quinoestrol in cereal bait to control the rat populations at a garbage dump. The site was baited six times at two week intervals. Significantly fewer female rats trapped after treatment were pregnant. Johnson and Barrett (1975) mixed diethylstilboestrol with peanut butter and offered it to feral house mice in an experimental enclosure for 16 days. There was a sharp decline in population following treatment. BDH 10131 in oatmeal bait was applied for a week to control the Norway rat population on a small island. Significantly fewer rats were caught after treatment; no sub-adult or pregnant animals were trapped in the 10 month period after treatment (Lazarus and Rowe, 1982). However, ethinyl oestradiol was found in this study to be highly unpalatable to female rats in paraffin blocks, even at a concentration as low as $50 \mathrm{mg} \mathrm{kg}^{-1}$ block. The animals consumed only small amounts of the bait during the first 2 days of treatment, and the amount of steroid ingested was not sufficient to interfere with their subsequent oestrous cycles or inhibit ovulation. Ethinyl oestradiol therefore cannot be used as a chemosterilant for rat control.

There have been no reports of the use of androgens for rodent control. The results of this study show that following treatment with methyl testosterone at a concentration of $500 \mathrm{mg} \mathrm{kg}^{-1}$ in paraffin blocks, all the females became pregnant after a slight delay. However, at a higher concentration of $5000 \mathrm{mg} \mathrm{kg}^{-1}$, although not as palatable as untreated blocks, methyl testosterone is effective in inducing almost immediate infertility in female rats and mice. This infertility persists throughout the duration of treatment, and lasts for several weeks after the cessation of treatment. Unfortunately, female rats develop a specific aversion to methyl testosterone when 
they are pregnant or lactating, making it impossible to deliver sufficient androgen to the fetuses or neonates to masculinize their brains, thereby inducing permanent sterility of all female offspring. In female mice, the methyl testosterone treatment produced such high levels of aggression that some animals died of their wounds, and some females even attacked and defeated the males. This could be highly disruptive to the social structure of feral mouse populations, and might make them much more prone to predation. The animals might also be more territorially defensive so that they would prevent incursions by other mice into the area. In contrast to the mice, the female rats did not show any signs of increased aggression, although the females lost their attractiveness to males.

Ingestion of $5000 \mathrm{mg}$ methyl testosterone $\mathrm{kg}^{-1}$ blocks for about 3 months also induces infertility in male rats owing to suppression of spermatogenesis. Although the primary objective of any chemosterilant campaign must be to target the females, long-term inhibition of male fertility is an added advantage.

So far there have been no reports of the use of gestagens for rodent control. We have shown that the potent new orally active gestagen, Org 5933, is highly palatable to rats and mice, and daily ingestion of about $20 \mathrm{~g}$ paraffin block containing as little as $4 \mathrm{mg} \mathrm{kg}^{-1}$ block of the compound is sufficient to stop ovulation completely in rats within 3 to 4 days of the start of treatment.

An added antifertility effect of Org 5933 is that ingestion by rats or mice during pregnancy can postpone parturition, leading to a high incidence of neonatal deaths, and even some maternal deaths in labour. It is hardly surprising that maintenance of gestagen levels during late pregnancy interferes with parturition, but it was remarkable that in the few instances in which rats or mice on treatment did give birth to live young, they all survived, at least for the first 5 days post partum. The generally accepted view, based largely on work in rats, is that progesterone withdrawal in the peripartum period is the trigger for the onset of lactogenesis (Kuhn, 1968; Cowie et al., 1980). The fact that our treated animals apparently lactated normally may cast some doubt on this hypothesis, although it is also possible that they may have consumed insufficient steroid in late gestation to inhibit lactation.

In the light of our results, the relative merits of the androgen methyl testosterone can be compared with the gestagen Org 5933 for rodent control. The androgen suffers from the disadvantage that the minimal effective concentration in the paraffin block needs to be about $5 \mathrm{~g} \mathrm{~kg}^{-1}$, giving a daily ingested dose of about $35 \mu \mathrm{gg}^{-1}$ body weight for a rat. At this concentration, the bait is beginning to lose its palatability, although a rat will consume about $1.2 \mathrm{~g}$ a day of the treated paraffin block. The advantage of the androgen is that it will inhibit ovulation almost immediately in rats and mice, and chronic administration for more than 3 months will induce male sterility, at least in rats. After cessation of treatment, it takes several weeks before the female returns to oestrus, and it will take even longer before male fertility returns. Unfortunately, any animals that are pregnant or lactating at the start of baiting will probably show an aversion to the bait, and hence give birth to normal litters of young. The major behavioural disruption that occurs in mice following methyl testosterone treatment is an added benefit; it would be interesting to see what behavioural changes were induced in feral rat and mouse populations.

The great advantage of the gestagen Org 5933 is its high palatability and high potency. The optimum concentration was found to be $4 \mathrm{mg} \mathrm{kg}^{-1}$ paraffin block. The high palatability could even be a disadvantage, because rats will consume up to $20 \mathrm{~g}$ of block per day, and mice about $5 \mathrm{~g}$ of block per day. This free-feeding could be expensive if there were a large number of animals in the population.

Another advantage of the gestagen is that there appears to be no aversion to it by pregnant or lactating animals. Thus all the individuals in a population could theoretically start to consume the compound at the commencement of baiting. This would result in a suppression of oestrus and ovulation within a few days in any animals that were cycling, and it would effectively prevent parturition or neonatal survival in any animals that were pregnant. However, any animals that were lactating could probably rear their young normally. Although we had insufficient compound to test its long-term effects on male fertility in rats or mice, it seems likely that it would inhibit spermatogenesis, as it is clearly an effective inhibitor of gonadotrophin secretion in females. Although the rapid resumption of female fertility following cessation of treatment is a potential disadvantage, male fertility would take much longer to return. This rapid reversibility would mean that there would be little chance of secondary poisoning if a treated animal was eaten by an avian or mammalian predator.

Our results show that paraffin blocks containing a mixture of cereal grains are highly palatable to rats and mice, and an ideal way of delivering a steroidal chemosterilant to rodent populations. The treated paraffin blocks are unlikely to be eaten by humans, carnivores, or birds. There is also no chance that the steroid can be leached out by rain, and it will be protected from decomposition in the block. The blocks could if necessary be secured inside baiting stations, e.g. drainpipes, to reduce exposure to nontarget species. We have already demonstrated the success of selective poisoning of rats and mice in yards containing tammar wallabies if the poison is presented in paraffin blocks in drainpipes (Gao, 1990b).

Most attempts to control rodent populations in the past have been therapeutic rather than prophylactic. People have waited until the population has built up to significant numbers before initiating a poisoning campaign, and this is a wasteful and inefficient way of controlling the problem. It would be far better to initiate long-term preventative strategies to stop the population from reaching plague proportions, and here chronic baiting with a palatable chemosterilant may have much to offer as a new control strategy. Although this concept was put forward more than 20 years ago (Howard, 1967; Marsh and Howard, 1973), it is only now that we have suitable compounds. The alternation of a conventional acute poisoning campaign with the chronic administration of a chemosterilant is the best way to prevent the development of resistance to the poison. The relatively high cost of the chemosterilant bait and the need for animals to consume it on a continuing basis for maintenance of the chemosterilant effect are obvious disadvantages, but the results presented here suggest that the chemosterilant approach is worth field testing to evaluate its cost effectiveness. 
We are very grateful to Muritoxin Pty Ltd, Melbourne for financial support, to the Pharma Division of Organon International, Oss, The Netherlands for supply of the gestagen, Org 5933, to Ian McCance for his valuable suggestions on some of the experiments, and to D. Clare for photographing the methyl testosterone treated female mice and the Figures.

\section{References}

Andrews RV and Belknap RW (1983) Efficacy of $\alpha$-chlorohydrin in sewer rat control Journal of Hygiene 91 359-366

Bajomi D, Gaál F, Láng F and Vámos G (1976) Efficiency of eradicating rats with paraffin baits International Pest Control 18 12-15

Bomford M (1990) A role for fertility control in wildlife management? Bureau of Rural Resources Bulletin 7 Eds J Caughley and A Furbank. Australian Government Publishing Service, Canberra

Brooks JE and Bowerman AM (1971) Estrogenic steroid used to inhibit reproduction in wild Norway rats Journal of Wildlife Management 35 444-449

Cowie, AT, Forsyth IA and Hart IC (1980) Hormonal Control of Lactation. Springer-Verlag, Berlin

Davis DE (1961) Principles for population control by gametocides Transactions of the North American Wildlife and Natural Resources Conference 26 $160-170$

Ericsson RJ, Downing HE, Marsh RE and Howard WE (1971) Bait acceptance by rats of microencapsulated male sterilant $\alpha$-chlorohydrin Journal of Wildlife Management 35 573-576

Gao Y (1990a) Aversion of female rats to paraffin blocks containing methyl testosterone during pregnancy and lactation Proceedings of 22nd Annual Conference, Australian Society for Reproductive Biology, p 47. University of Western Australia, Perth, September 24-26
Gao Y (1990b) Selective eradication of rats by poisoning with anticoagulant in an enclosure containing tammar wallabies International Pest Control 32 152-154

Greaves JH (1985) The present status of resistance to anticoagulants Acta Zoologica Fennica 173 159-162

Howard WE (1967) Biocontrol and chemosterilants. In Pest Control: Biological Physical and Selected Chemical Methods, pp 343-386 Eds WW Kilgore and RL Doutt. Academic Press, New York and London

Johnson RF and Barrett GW (1975) Effects of diethylstilbestrol on feral house mouse (Mus musculus L.) population dynamics under experimental field conditions Journal of Applied Ecology 12 471-477

Knipling EF (1959) Sterile male method of population control Science 130 902-904

Knipling EF and McGuire JU (1972) Potential role of sterilization for suppressing rat populations. A theoretical appraisal Technical Bulletin No. 1455, pp 1-27. US Department of Agriculture, Agricultural Research Service, Maryland

Kuhn NJ (1968) Lactogenesis in the rat Biochemical Journal 106 734-748

Lazarus AB and Rowe FP (1982) Reproducton in an island population of Norway rats, Rattus norvegicus (Berkenhout), treated with an oestrogenic steroid AgroEcosystems 8 59-67

Marsh RE (1988) Chemosterilants for rodent control. In Rodent Pest Management, pp 353-367 Ed. I Prakash. CRC Press, Florida

Marsh RE and Howard WE (1969) Evaluation of mestranol as a reproductive inhibitor of Norway rats in garbage dump Journal of Wildlife Management 33 133-138

Marsh RE and Howard WE (1973) Prospects of chemosterilant and genetic control of rodents Bulletin of the World Health Organization 48 309-316

Meehan AP (1984) Rats and Mice: Their Biology and Control. Rentokil Limited Sussex

World Health Organization (1987) WHO Laboratory Manual for the Examination of Human Semest and Semen-cervical Mucus Interaction. Cambridge University Press, Cambridge. 